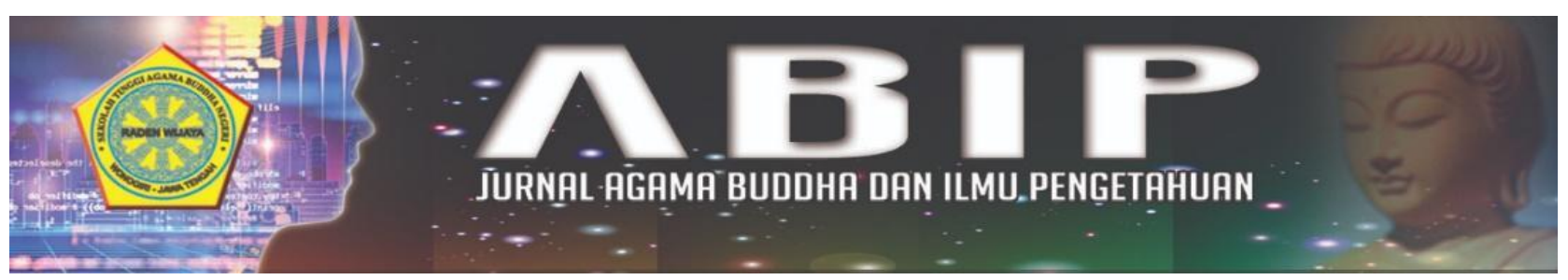

\title{
PERSPEKTIF AGAMA BUDDHA TERHADAP BERBAGAI MACAM UPACARA TRADISI MASYARAKAT TIONGHOA
}

\author{
Widiyanto \\ STIAB Jinarakkhita Lampung \\ wyanto1979@gmail.com
}

\begin{abstract}
Abstrak
Berbagai macam cara yang dilakukan oleh masyarakat Buddha keturunan Tionghoa dalam mempraktikkan upacara yang merupakan tradisi leluhur yang masih dilakukan dan dipegang teguh. Tujuan penelitian adalah untuk meluruskan pandangan agama Buddha terhadap pelaksanaan upacara tradisi Tionghoa, serta menjelaskan persamaan dan perbedaan keduanya. Berdasarkan data yang diperoleh, jenis penelitian yang digunakan adalah penelitian studi pustaka (library research). Menurut bidang yang diteliti penelitian yang dilakukan termasuk di dalam jenis penelitian kualitatif. Subyek dalam penelitian ini adalah peneliti sendiri. peneliti langsung berlaku sebagai alat penelitian utama (key instrument) yang mana melakukan proses penelitian secara langsung dan aktif mengumpulkan berbagai materi atau bahan yang berkaitan dengan agama Buddha dan tradisi Tionghoa. Hasil penelitian menunjukkan bahwa: (1) Tradisi Budaya Tionghoa sangat beragam, komplek dan mempunyai nilai religius yang tinggi; (2) Tradisi Budaya Agama Buddha adalah tradisi religius, semua bentuk budaya di dalamnya mengarah pada pencapaian kesucian; (3) Tradisi Budaya Tionghoa lebih ekploratif dalam nilai-nilai sosial dan perjuangan, sementara tradisi budaya Buddhis bersifat universal; (4) Kedua Tradisi dapat saling mengisi untuk menghasilkan kehidupan beragama yang harmonis; (5) Praktik Tradisi budaya Buddhis tidak hanya membuahkan kehidupan bahagia di surga tetapi juga dapat merealisasi tujuan akhir dari kehidupan yaitu nibbana.
\end{abstract}

Kata kunci: daftarkan 3 hingga 4 kata kunci di sini.

\begin{abstract}
There are various ways in which the Buddhist community of Chinese descent practices ceremonies which are ancestral traditions that are still practiced and adhered to. The purpose of this research is to straighten out the Buddhist views on the implementation of traditional Chinese ceremonies, as well as to explain the similarities and differences between the two. Based on the data obtained, the type of research used is library research. According to the research field, the research conducted is included in the type of qualitative research. The subjects in this study were the researchers themselves. The researcher directly acts as the main research tool (key instrument) which carries out the research process directly and actively collects various materials or materials related to Buddhism and Chinese traditions. The results showed that: (1) Chinese cultural traditions are very diverse, complex and have high religious values; (2) Cultural Traditions Buddhism is a religious tradition, all forms of culture in it lead to the attainment of holiness; (3) Chinese cultural traditions are more explorative in social values and struggles, while Buddhist cultural traditions are universal; (4) The two traditions can complement each other to produce a harmonious religious life; (5) The practice of Buddhist cultural traditions not only results in a happy life in heaven but can also realize the ultimate goal of life, namely nibbana
\end{abstract}

Keywords: Agama Buddha, Tradisi Tiongho 


\section{PENDAHULUAN}

Sebelum mengenal agama-agama manusia hidup berdasarkan nilai-nilai/ norma yang telah disepakati bersama dan jika terjadi suatu pelanggaran maka dikenai sangsi sesuai tingkat pelanggarannya. Cara hidup dengan mewarisi adat kebiasaan turun-temurun dari nenek moyang seperti ini kemudian hari dikenal dengan tradisi budaya.

Tradisi budaya suatu bangsa dapat dipakai sebagai tolok ukur kemajuan suatu peradaban. Hal itu dapat dilihat dari peninggalan-peninggalan yang ada, seperti: karya seni; benda-benda purbakala, bentuk bangunan, adat-istiadat atau tatakrama, dan sistem kepercayaan. Sebagai contoh; bangunan piramid menunjukkan tingkat kemajuan tradisi budaya Mesir di jaman Fir'aun, Borobudur menunjukkan tingkat kemajuan tradisi budaya Jawa di jaman Smaratungga dan Tembok Raksasa (great wall) menunjukan kemajuan tradisi budaya Tionghoa di jaman Dinasti Chin.

Nilai tradisi budaya suatu bangsa lebih bersifat lokal dibandingkan dengan Agama Buddha yang universal. Namun demikian tradisi budaya juga syarat dengan niai-nilai yang penting dan berharga, seperti: nilai kemanusiaan, patriotisme dan kebersamaan. Karena tidak memahami tradisi budaya suatu kelompok tertentu terkadang menjadi pemicu konflik yang mengarah pada perpecahan dan peperangan.

Keberadaan Etnis Tionghoa bagi perkembangan umat Buddha Indonesia amat sangat berarti. Mereka memiliki Tradisi budaya sangat beragam yang kaya akan nilainilai moralitas, bakti pada keluarga dan negara. Beberapa tradisi budaya itu diantaranya adalah: Tradisi Tahun Baru Imlek, Tradisi Sembahyang kubur/ leluhur, Tradisi Kau Chung, Tradisi Mandi U-Shi, Kue Bulan, Kue Bak Cang, Festival Naga, Barongsai, dan Ta Tung / Lauya.

Kurangnya pengetahuan keragaman tradisi budaya di lingkungan Tionghoa ini kadang mengaburkan arti religius agama yang mereka anut. Hal itu dapat terjadi diantaranya karena para misionaris berusaha untuk membungkus agama sesuai tatacara tradisi budaya setempat dengan harapan agama yang diwartakan dapat diterima sehingga mempunyai pengikut yang banyak. Hal itu juga terjadi dilingkungan umat Buddha tertentu yang mempunyai pandangan bangga dengan memiliki jemaat yang banyak. Akan tetapi dilain sisi justru alkulturasi tradisi budaya seperti kadang menjadi bumerang bagi kemurnian ajaran agama yang sedang diwartakan.

Kewajiban umat Buddha diantaranya
adalah meluruskan pandangan,
menginterpretasi tradisi budaya apa saja, terlebih tradisi Tionghoa khususnya agar dapat berada pada posisi yang sebenarnya, sehingga lebih terhormat dan mempunyai nilai kebajikan universal yang pada akhirnya akan memberikan kontribusi terhadap kemajuan batin umat Buddha itu sendiri. Sebagai contoh misalnya; Im Lek, periode pergantian tahun masyarakat Tionghoa yang dirayakan cukup meriah ini kedudukannya sama seperti merayakan hari raya agama pada tradisi agama tertentu. Lauya / Ta Thung dianggap Dewa yang dapat melindungi dan mengatasi masalah, ketika sakit atau mengalami kesulitan.

Karena terjadi alkulturasi antara Buddha Dhamma dengan tradisi budaya Tionghoa maka banyak orang beranggapan bahwa praktek Lauya / Ta Thung adalah produk dan tradisi agama Buddha. Kenyataan yang terjadi dilapangan sebenarnya dalam praktekanya para Lauyal Ta Thung menggunakan atribut-atribut yang hampir sama dengan praktik ritual agama Buddha Mahayana khususya, seperti memasang lilin, hio, air dan buah sekalipun terkadang para Lauya ini ada yang menyimpang dalam praktiknya menggunakan daging, arak dan darah. Generalisasi yang tidak tepat seperti ini umat agama lain terkadang memandang sinis terhadap umat Buddha, sekalipun ada umat Buddha yang tidak tahu menahu tentang praktek Lauya.

Buddha Gotama mengkritik semua praktik yang berorientasi pada pamer kekuatan (ilmu gaib), mengaku telah mencapai tingkat kesucian, untuk mencari penghidupan, popularitas dan keuntungan pribadi. Hal-hal seperti itu melanggar Vinaya kebhikkhuanya, bahkan dapat dikeluarkan dari Sangha (salah satu Parajika). Praktik Lauya dalam kehidupan sehari-hari umumnya 
bermotivasi menolong bukan untuk mencari keuntungan pribadi tetapi akhir-akhir ini praktik Lauya/Ta Thung dieksplorasi orang tertentu untuk tujuan komersial.

Eksplorasi tradisi budaya berdampak menguntungkan dan sekaligus merugikan. Menguntungkan karena tradisi budaya yang tidak dikenal masyarakat dapat dikenal masyarakat luas. Merugikan karena eksplorasi budaya terkadang mengabaikan nilai-nilai religius yang terkandung didalamnya sehingga terkesan biasa-biasa saja. Tidak mendasar dan hanya mempunyai nilai estetika belaka.

Dampak buruk lainya adalah generasi muda menilai bahwa tradisi budaya itu hanya bersifat tahayul, dongeng, tidak mendasar dalam kehidupan sehari-hari dan tidak bermanfaat sehingga mengurangi minat akan memahami makna sesungguhnya dari tradisi budaya tersebut. Disisi lain karena tidak memahami Dhamma, banyak umat Buddha sekalipun berpendidikan tinggi, kaya dan berkecukupan secara materi ketika menghadapi masalah yang pelik mengenai rumah tangga, pekerjaan, kesehatan, asmara, dan keberuntungan pergi ke paranormal, dukun atau Lauya untuk meminta tolong.

Tradisi budaya adalah keseluruhan gagasan dan karya manusia yang harus dibiasakan dengan belajar, beserta keseluruhan dari hasil budi dan karyanya itu. (K.Wijaya Mukti , 2003)

Sedangkan orang Tionghoa adalah orang yang berasal dari Tiongkok atau Cung Kuok. Istilah Tionghoa berasal dari kata Tiong yang menunjukan marga Tiong dari Dinasti Chin yang terkenal sadis dan kejam. Penggunaan kata Tionghoa dimaksudkan untuk menghindari pandangan bahwa mereka orang yang sadis dan kejam.

Berdasarkan uraian diatas maka dapat penulis simpulkan sebagai berikut: Tradisi Budaya Tionghoa adalah keseluruhan gagasan dan karya orang Tionghoa yang dipakai sebagai pedoman hidup, terdiri dari kosepkonsep, teori-teori dan metode-metode yang merupakan pengetahuan dan keyakinan dalam memenuhi kebutuhan - kebutuhannya sebagai manusia.

$$
\begin{aligned}
& \text { Cornelis Wowor dalam bukunya } \\
& \text { Pandangan Sosial Agama Buddha }
\end{aligned}
$$

menyebutkan Terdapat tiga cara Buddha mengenalkan ajaraNya yaitu:

\section{Dengan Cara Revolusi}

Cara revolusi dimaksudkan Buddha untuk merombak secara menyeluruh dan radikal terhadap sitem kepercayaan, adat tradisi dan budaya yang telah ada. Seperti perombakan filsafat Anatta (Tanpa aku yang kekal). Penolakan Beliau terhadap upacaraupacara korban maupun penolakan beliau terhadap sistim kasta.

\section{Dengan Cara Reinterpretasi}

Cara reinterpretasi dimaksudkan Buddha untuk memikirkan dan memberi makna secara baru terhadap sesuatu yang telah ada dan dianggap tidak bermanfaat. Contohnya adalah ketika Buddha memberi makna baru terhadap kebiasaan mandi berendam di sungai yang suci dipercaya dapat menghapuskan noda dan dosa. Selanjutnya Buddha bersabda" Sungai tak dapat mensucikan orang yang berbuat jahat. Berendamlah dalam Sila, dan buatlah semua makluk merasa aman, yaitu dengan tidak berbicara bohong, tidak menyakiti makluk hidup. (Majjhima Nikaya I, hlm 39)

\section{Dengan Cara Rekonstruksi}

Cara rekonstruksi dimaksudkan Buddha untuk menciptakan tatanan baru diluar keduasistem yang telah ada tersebut. Beliau memperkenalkan Empat Kebenaran mulia (Catur Arya Saccani) dan Delapan jalam mulia dalam mengatasi problematika kehidupan.(Cornelis Wowor, 2004)

Tradisi budaya Buddhis berkembang dari ajaran dan teladan hidup Buddha seperti: cara berpikir, berbicara, bertindak dan bertindak, yang bertitik tolak dari pencapaian penerangan sempurna. Dalam perkembangannya tradisi budaya Buddhis tidak hanya berpengaruh di India melainkan meluas menjadi salah satu bagian dari kebudayaan keagamaan atau kebudayaan spiritual, maupun kebudayaan material dunia. Berkaitan dengan tradisi budaya, menurut Koencoro Ningkrat yang dikutp Wijaya Mukti menjelaskan:

Terdapat tiga wujud kebudayaan yang saling berkaitan, yaitu; 1). Wujud idiil (ide dan adat yang mengatur laku berupa sistem nilai budaya, norma, hukum, peraturan), 2). Sistem 
sosial, aktifitas/ tingkah laku manusia menurut pola tertentu berdasarkan adat tata kelakuan, 3 ). Benda-benda fisik karya manusia. (Wijaya Mukti, 2003)

\section{METODE}

Penelitian ini adalah penelitian studi pustaka (library research) dengan pendekatan kualitatif yang mengambil fokus kajian pada upacara tradisi Tionghoa dalam sudut pandang agama Buddha yang bertujuan untuk mengkaji bagaimana kaitan tradisi Tionghoa dengan ajaran Buddha, serta mengungkap fungsi, tujuan dan faktor-faktor yang membedakannya.

Sumber penelitian diperoleh dari sumber data primer dan sumber data sekunder. Sumber data primer, yaitu sumber data yang memberikan data secara langsung dalam penelitian ini. Adapun yang dimaksud sebagai sumber data primer yaitu Kitab Suci agama Buddha, artikel, serta jurnal yang ada kaitannya dengan penelitian ini. Sumber data sekunder, yaitu sumber tambahan atau sumber pendukung yang juga berkaitan dengan penelitian tersebut. Data ini diperoleh dari buku ataupun literatur yang terkait dengan tema penelitian tersebut.

Subjek / informan dalam penelitian ini adalah peneliti sendiri. peneliti langsung berlaku sebagai alat penelitian utama (key instrument) yang mana melakukan proses penelitian secara langsung dan aktif mengumpulkan berbagai materi atau bahan yang berkaitan dengan agama Buddha dan tradisi Tionghoa. Guna menemukan hasil penelitian ini, maka peneliti menempuh beberapa langkah yaitu pengumpulan data, pengolahan data atau analisis data, penyusunan laporan serta penarikan kesimpulan. Proses ini dilakukan guna mendapatkan hasil penelitian secara

\section{HASIL}

Masyarakat Tionghoa yang sebagian besar memeluk agama Buddha di Indonesia ada sebagian yang sudah meninggalkan tradisi budaya, tetapi sebagian besar masih melaksanakannya dalam kehidupan seharihari. Sang Buddha tidak melarang umatnya untuk meninggalkan tradisi budaya, tetapi menganjurkan untuk menerimanya dan hidup dengan tradisi tersebut apabila tradisi itu membawa manfaat dan kemajuan dalam kehidupannya.

Demikian juga, orang Tionghoa yang memeluk agama Buddha dapat menjalankan tradisi yang sudah turun-temurun dengan dilandasi kebijaksanaan. Tradisi-budaya tersebut di antaranya adalah tradisi pemujaan terhadap para leluhur dan para Dewa, Festival Musim Semi, Praktek Cenayang Lauya/ Ta Thung pada acara Cap Go Meh, Barongsai, Tradisi Mandi $U$-Shi, Tuan U Ciek, air U-Shi, kue Bak Cang dan Kwe Cot, Tradisi sembahyang Kuburan, Ceng Beng, Legenda Festival Kue Bulan, Kiet Fun / Adat Perkawinan Tradisional Tionghoa, Tien Chon yang sudah berlangsung sejak dahulu kala.

\section{Tradisi puja}

Memanggil Dewa (Devata Aradhana) dalam tradisi Tionghoa adalah untuk meberi penghormatan, sekaligus menunjukkan rasa bakti kepada para dewa atas perlindungan dan bimbingannya. Tepai dalam tradisi Buddha adalah mengajak para Dewa turut serta dalam mendengarkan dan merenungkan kembali Dhamma Buddha lewat Pembacaan Paritta.

"Semoga para dewa di segenap alam datang, kesini mendengarkan Ajaran Kebenaran Buddha, Raja para bijaksana, yang membimbing ke surga dan kebebasan. Datanglah para dewa yang bersemayam di surga, yang berada ditingkat alam napsu ataupun di tingkat alam berbentuk; juga dewa bumi yang bersemayam di vimana (tempat menyenangkan/bersemayam para dewa) atau di puncak gunung, di jurang, di angkasa, di pulau, di kota, di desa, di pepohonan, di hutan belukar, di sekitar rumah atau di sawahsawah dan ladang; juga para yakkha, gandhabba, dan naga yang bersemyam di perairan, daratan atau pun di perbukitan. Silahkan mereka yang berada disekitar ini mendengarkan sabda Buddha, Raja para bijaksana, seperti beikut ini. Sekarang tiba saatnya mendengarkan Dhamma (3X).

Jadi tradisi puja adalah untuk melatih kualitas batin seseorang bukan untuk meminta berkah. Puja dapat berupa materi ( amise puja) seperti persembahan Lilin, Hio/dupa, Air, Bunga, Buah-buahan dan makanan. Dapat juga berupa perbuatan/ prilaku ( pati-pati puja).

Perayaan Tahun Baru 
Perayaan Pergantian tahun telah dirayakan sejak dulu kala, untuk menandakan pergantian tahun. Makna relegius dari perayaan ini adalah untuk intropeksi diri, mengevalusi perjalanan hidup selama setahun. Mana yang perlu ditingkatkan dan mana yang harus dihilangkan.

\section{Praktek Cenayang (Ta Thung)}

Kesurupan / terpengaruh makluk halus (Ta Thung) oleh penghuni alam rendah seperti; petta, asura dan yakkha, ada kalanya meminta sesuatu yang melanggar kesusilaan. Yakkha, makluk halus jahat yang terkenal sakti dalam usahanya memenuhi keinginan, seperti; makan, minum sering dengan caracara memaksa / mempengaruhi orang yang kesadarannya lemah.

Terdapat duapuluh lima kondisi yang menyebabkan lemahnya kesadaran, seperti; 1). kemarahan, 2). permusuhan, 3). kemunafikan, 4). kecongkakan, 5). keirihatian, 6). ketamakan, 7). kebohongan, 8). pengkhianatan, 9). keras kepala, 10). suka melawan, 11). kesombongan, 12). suka pujian, 13). pandangan yang berlebihan, 14). ketidakpedulian 15)keengganan, 16)teman yang jahat, 17). rasa ngantuk dan malas, 18). obyek yang terlihat, 19). suara, 20). bau, 21). cita rasa, 22). sensasi sentuhan, 23). rasa lapar, 24). rasa haus, 25). ketidak puasan.

Dalam praktik $T a$ Thung, masayarakat Tradisional Tionghoa dipakai untuk meramaikan suasana Cap Go Meh dan membersihkan suasana dari roh-roh jahat, hantu, yakkha dan peta. Ada kalanya untuk konsultasi usaha dan rumah tangga.

\section{Berendam di sungai}

Untuk membersihkan diri dari dosa, karma buruk, mendapatkan berkah dan umur panjang harus diimbangi dengan tekad dan kemauan yang kuat. Kepercayaan yang membuta praktik berendam di sungai pernah dikritik Buddha. Hendaklah manusia berendam dalam sila untuk mencapai kesempurnaan hidup.

\section{Rasa bakti}

Bakti adalah salah satu sifat mulia yang harus dikembangka oleh mereka yang ingin mencapai kesempurnaan (Jalan Bodhisatva).

Bakti pada orang tua berarti melayani dan memenuhi kebutuhan hidupnya. Juga memberikan penghormatan dan sesajian jika telah meninggal dunia. Meneladani semangat dan perjuangan para pahlawan demi kemerdekaan, kesejahteraan dan kemakmuran. Terhadap mereka itu kita harus memberi penghormatan yang tulus.

Apapun mereknya jika memenuhi kedelapan hal berikut ini dapat dipraktikan sebagai pedoman hidup. Delapan hal itu adalah bertujuan sebagai berikut ini: 1). mengurangi rangsanagan indera dan pikiran, 2). membebaskan diri dari dukkha/penderitaan, 3). menghindarkan diri dari pemupukan kekotoran batin, 4). merasa puas dengan keterbatasan yang ada, 5). memberikan kepuasan dan kebahagiaan pada apa yang telah dimiliki, 6). meningkatkan semangat dalam usaha, 7). memberikan rasa mudah untuk dirawat atau dibantu, 8). menimbulkan rasa suka untuk tinggal di tempat sunyi demi kemajuan batinnya.

\section{Hasil}

Setelah melakukan deskriptip data penelitian, maka penulis akan melakukan analisis data tersebut dengan cara membandingkan kedua tradisi budaya orang Tionghoa dengan tradisi budaya agama Buddha. Tentu terjadi kesamaan dan peerbedaan sebagai ciri khas sudut pandang dari kedua faham itu. Hal itu dapat dilihat dari hasil perbandingan berikut ini.

\section{Persamaan}

Tradisi budaya Tionghoa

1. Sarana Ritual (lilin, hio/ dupa, buah, bunga, air, sarana membuat obat).

2. Menjunjung rasa bakti pada leluhur.

3. Ingin mencapai kesempurnaan, sebagai dewa atau malaikat.

4. Kesempurnaan prilaku.

Agama Buddha

1. Sarana Ritual (lilin, hio/dupa, buah, bunga, air, obat-obatan, makanan.

2. Menjunjung rasa bakti pada leluhur.

3. Ingin mencapai kesempurnaan arahat.

4. Kesempurnaan prilaku.

\section{Perbedaan}


Berbedaan mendasar tradisi budaya orang Tionghoa dan tradisi agama Buddha yaitu:

\section{Tradisi budaya Tionghoa}

Sarana berbuat kebajikan ada kalanya menggunakan pengorbanan makluk hidup seperti ayam dan bebek. Ada kalanya masih mempertontonkan kekuatan gaib untuk tujuan-tujuan tertentu yang tidak mengarah pada kesucian, menjadi Dewa adalah tujuan orang Tionghoa tradisional, karena menganggap menjadi Dewa dapat hidup abadi. Imlek identik dengan hari raya agama tradisional Tionghoa bahkan ada yang mengklaim sebagai hari raya Konghucu.

\section{Tradisi agama Buddha}

Dalam tradisi Buddha tidak ada makluk hidup yang dikorbankan. Tidak ada pertunjukan kekuatan gaib/keajaiban, hal itu justru mempertebal keegoisan. Keajaiban dalam Dhamma yaitu dapat memahami kebenaran apa adanya. Menjadi Dewa bukan tujuan utama, karena masih akan mengalami kelahiran kembali. Keabadian dicapai Umat Buddha dengan mencapai kesucian arahat. Hari raya dalam agama Buddha mempunyai latar belakang relegius yang dapat mengarah pada kesucian.

\section{KESIMPULAN}

Dapat disimpulkan bahwa:

1. Agama adalah segenap kepercayaan (kepada Tuhan, Dewa dan sebagainya) serta dengan ajaran kebaktian dan kewajiban-kewajiban yang bertalian dengan kepercayaan itu; misalnyanya Islam; Buddha; Kristen. Agama didefinisikan sebagai adat dan kebiasaan atau tradisi yang digunakan manusia untuk berkomunikasi dengan roh-roh, oleh karena itu agama adalah sebagian dari budaya. Sedangkan Budaya adalah cara hidup suatu pendduduk/ kelompok dalam memenuhi kebutuhankebutuhannya sebagai manusia.

2. Agama Buddha adalah ajaran kebenaran (Dhamma/Dharma) yang diajarkan oleh Buddha Sakyamuni. Agama Buddha adalah jalan hidup yang benar untuk kedamaian dan kebahagiaan semua makluk hidup. Buddhime merupakan suatu metode untuk lepas dari kesengsaraan dan menemukan pembebasan. Ajaran Sang Budddha tidak terbatas pada satu bangsa atau ras. Ajaran ini juga bukanlah suatu syahadat atau iman semata. Ini adalah ajaran untuk seluruh alam semesta. Ini adalah ajaran untuk sepanjang masa. Tujuannya adalah pelayanan yang tidak egois, niat baik, kedamaian, keselamatan, dan pembebasan dari penderitaan.

3. Dengan demikian menurut agama Buddha, Tradisi Budaya adalah berfungsi sebagai ornamen yang memperindah agama sehingga menarik bagi masyarakat.

4. Orang Tionghoa dapat mengikuti tradisi budaya yang telah turun temurun walaupun sama sekali tidak memiliki nilai-nilai religius, asalkan dalam pelaksanaannya tidak mengatas namakan agama tertentu apa lagi agama Buddha.

5. Buddhisme sangat terbuka terhadap berbagai adat tradisi, budaya yang mempunyai nilai-nilai universal, membawa kemajuan batin, kebahagiaan dan kesejahteraan seperti: prikemanusiaan (humanisme), patriotisme, kerelaan, kerendahan hati. Dengan Tradisi Budaya dalam pandangan agama buddha dapat memberi bantuan psychologis bagi beberapa orang sesuai tingkat spiritualnya.

6. Banyaknya ritual pada Tradisi Tionghoa lebih dilatar belakangi sebagai rasa bakti yang tulus akan pengabdian dan dedikasi yang tinggi akan sikap melayani.

7. Terdapat korelasi yang saling mempengaruhi diantara tradisi Tionghoa dan agama Buddha.

\section{Daftar Pustaka}

Asali,x.f, (2008), Aneka Budaya Tionghoa Kaimantan Barat, Pontianak: Muare Public Relation

Dhammananda, Sri.(2002), Keyakinan Umat Buddha. Jakarta: Yayasan Penerbit Karaniya.

Jusuf, Tedy. (2000), Sekilas Budaya Tionghoa di Indonesia. Jakarta: PT. Bhuana Ilmu Populer - Kelompok Gramedia. 
Kusuma, G. ., Yonata, H. ., \& Handoko, A. L. . (2020). Peranan Kebudayaan Tionghoa terhadap Perkembangan Agama Buddha: Studi Kasus di Desa Rancaiyuh Kecamatan Panongan Kabupaten Tangerang. Jurnal Ilmu Agama Dan Pendidikan Agama Buddha, 2(2), 117130. Retrieved from https://journalstabdharmawidya.ac.id/ind ex.php/contents/article/view/19

Panjika. (2004), Kamus Umum Buddha Dharma. Jakarta: Tri Sattva Buddhist Centre.

Suharto. (2003), Kamus Populer Mandarin Indonesia. Jakarta: PT. Gramedia Pustaka Utama.

Tithayanno, bhikkku. (2006), Sembahyang Leluhur menurut Buddha Dhamma, Seminar.

Welly, Septiyana. (2020), Tradisi Imlek dan Perubahannya pada Masyarakat Tionghoa Vihara Dharma Agung Tanggamus Lampung. Lampung: Fakultas Ilmu Sosial dan Politik.

Widya, Dharma K. (2006), Dharma Ajaran Mulia Sang Buddha. Jakarta: PP Magabudhi.

Winarsi, Agus Hendrik. (2003), Mengenal Hari Raya Konfusiani. Semarang: Effhar Semarang. 